\title{
Research on Team Faultlines: A Literature Review
}

\author{
Caihong Zhang, Chunlin Liu \\ School of Management, Jinan University, Guangzhou, China \\ Email: hrliuchunlin@126.com
}

How to cite this paper: Zhang, C.H. and Liu, C.L. (2019) Research on Team Faultlines: A Literature Review. Journal of $\mathrm{Hu}$ man Resource and Sustainability Studies, 7, 37-54.

https://doi.org/10.4236/jhrss.2019.71004

Received: February 26, 2019

Accepted: March 17, 2019

Published: March 20, 2019

Copyright $\odot 2019$ by author(s) and Scientific Research Publishing Inc. This work is licensed under the Creative Commons Attribution International License (CC BY 4.0).

http://creativecommons.org/licenses/by/4.0/

\section{cc) (i) Open Access}

\begin{abstract}
Team faultlines, which is based on the diversified features of team members, is a potential line dividing team into several sub-teams. In recent years, more and more researchers pay attention to this new perspective. This paper reviews literature from theoretical foundation, measuring method, effect mechanism and so on several aspects, and advances the research prospect hoping to provide reference for future research.
\end{abstract}

\section{Keywords}

Team Diversity, Team Faultlines, Sub-Team, Team Performance

\section{Introduction}

In order to cope with the complex environment and achieve organizational goals, more and more enterprises adopt the team as the mode of operation. However, with the diversity of team members, the differences between team members lead to poor communication and team conflicts. Due to the differences in gender, age, education background, cognitive and other characteristics among team members, the team gradually differentiated gradually and formed two or more internal homogeneous and heterogeneous between sub-teams finally [1]. If this internal differentiation is not intervened, it will lead to form the cognition and behavior of "insiders" and "outsiders", which will make it difficult for the sub-teams to cooperate effectively, ultimately damaging team performance [2].

Research on how team structure attributes, including team diversity, affect team processes and outcomes, is becoming the focus of organizational management research [3] [4]. We can't grasp the overall characteristics of team members if only investigating the distribution of a feature among team members. Only through a comprehensive investigation of multiple characteristics of team 
members and their synergistic effects can we better understand the impact of diverse structures on team processes and outcomes. The team faultlines is a potential line dividing team into several sub-teams because of the multiple features difference of team members [1] [4]. Although scholars have done a lot of research on the relationship between team faultlines and team outcomes, they have not reached a consensus conclusion. Some scholars believe that team faultines will cause the cooperation to be only a form, cause conflicts and reduce team cohesiveness and performance [1] [3] [5] [6]. While other scholars believe that team faultlines may provide opportunities for sub-teams to share diverse information and promote thoughtful thinking, learning and innovation, thereby improving quality of decision-making and team performance [7] [8]. The inconsistency shows that there is a lot of space waiting for exploring in the field of team faultlines, and it is also urgent to review the existing research. Therefore, this paper systematically reviews the existing research from theoretical foundation, measuring method, effect mechanism and so on several aspects, and advances the research prospect, and finally puts forward future research direction.

\section{Theoretical Foundation}

Throughout the previous research, team faultlines is mainly based on the three theories: social-categorization theory, same-sex attraction pattern and information decision theory.

1) Social-categorization theory believes that individuals have a strong sense of self-examination and evaluation by comparing with others. When finding similar characteristics from other, they will show a strong sense of identity and find out the difference between "insiders" and "outsiders" as much as possible [2]. In pursuit of positive self-evaluation, individuals tend to overestimate "insiders" and underestimate "outsiders". The more similar features among individuals, the deeper the insider prefer, and the more obvious the boundary between sub-teams (team faultlines) [9]. As a result, the estrangement and conflict between the two subgroups are gradually deepened, and the communication and sharing between "insiders" and "outsiders" are gradually reduced, which will finally bring negative effects on the team output.

2) Same-sex attraction pattern believes that the forces of mutual attraction between individuals and individuals are derived from similar attitudes, beliefs, and traits among team members [10]. Similar individual characteristics can cause similar cognition about people's attitudes and values, thus forming a strong interpersonal attraction and promoting communication and interaction between individuals; conversely, may lead to less interpersonal communication. This significant difference in interaction with different individuals will exacerbate the tendency of team differentiation and form team faultlines [11]. For their views and beliefs can be supported, they tend to belong to the sub-group rather than the team, which has a negative impact on team cohesiveness and performance. 
3) Information decision theory believes that the differences in the educational background of team members will lead to different perspective and capability in selecting information resources, and resulting of conclusions are also different. Therefore, members with similar concepts and knowledge background tend to form sub-teams to gain mutual support from the team. The difference of information selection between members is greater, the differentiation of team is greater, the more obvious the team faultlines it is. The differences in task-related characteristics make the team have sufficient resources to solve unconventional problems, avoid the team falling into group thinking and bring more creativity and innovation performance.

\section{Measuring Method}

The author reviews relevant literatures and finds that the measurement of team faultlines has gone through the process from qualitative to quantitative to construct measurement. However, there is no simple and scientific method accepted by scholars.

1) Qualitative Measurement. Lau and Murnighan (1998) qualitatively described the strength of team faultlines based on the number of consistent characteristics of team members and the possible division of sub-teams. When the number of the same features of the members in the sub-team is certain, the less the sub-teams are divided, the strength of the faultlines is stronger. Conversely, when the sub-teams are divided certainly, the more the same features of the members in the sub-team, the strength of the faultlines is stronger [1]. Barkema and Shvyrkov (2007) [12] borrowed Lau and Murnighan's measuring method to qualitatively measure the strength of team faultlines using the Aligns-Ways model. The Aligns represents the number of same features of members within the sub-team; Ways represents the number of ways in which teams can be divided into different sub-teams based on the same feature distribution of team members.

2) Quantitative Measurement. Quantitative measurement contains three types: Fau, Faultlines Distance, FLS.

a) Thatcher et al. (2003) proposed a method for measuring team faultlines and gave a formula (Fau) for calculating the strength of team faultlines [8].

$$
\operatorname{Fau}_{g}=\frac{\sum_{j=1}^{p} \sum_{k=1}^{2} n_{k}^{g}\left(\bar{x}_{j k}-\bar{x}_{j}^{2}\right)}{\sum_{j=1}^{p} \sum_{k=1}^{2} \sum_{i=1}^{n_{k}^{g}}\left(\bar{x}_{i j k}-\bar{x}_{j}\right)^{2}}
$$

In which $p$ denotes the number of feature, $n_{k}^{g}$ denotes the number of members in the sub-teams $k$ produced by the $g$-th segmentation method (divided into two sub-teams), $\bar{x}_{j k}$ denotes the mean of the feature $j$ in sub-team $k, \bar{x}_{j}$ denotes the mean of overall feature $j$ in team $k$, and $\bar{x}_{i j k}$ denotes the value of the member $i$ on feature $j$ in sub-teams $k$. In all g segmentation methods, the maximum value of the $\mathrm{Fau}_{g}$ is taken as the strength of team faultlines. The Fau value theory of Thatcher et al. (2003) is the most widely used methods for calculating 
team faultlines, laid the foundation for the calculation of team faultlines. Using numerical variables to obtain the strength of team faultlines, which facilitates the comparison among intergroup. The calculation can determine the relationship between the team members and the sub-teams. To reduce the calculated amount, this method limits the number of sub-teams 2 .

b) Bezrukova et al. (2009) introduced the concept of faultlines distance to measure the dispersion of the two sub-teams in demographics. It filled the gap of Fau (the strength of faultlines) which only reflect the degree of consistency of characteristic [2].

$$
D_{e}(X, Y)=\sqrt{\sum_{i}\left(x_{i}-y_{i}\right)^{2}}
$$

In which $x_{i}$ denotes the mean of $i$-th feature of one sub-teams, and $y_{i}$ is the mean of the feature corresponding to another sub-team. Only using $\operatorname{Fau}^{\star} D_{e}(X$, $Y)$ can we ensure that the homogeneity within sub-teams and the differences between sub-teams are considered.

c) Shaw (2004) measured the degree of alignment within sub-teams and the differences between sub-teams. Shaw refers to the alignment of other feature of the sub-team members as IA (the Internal Subgroup Alignment), and the alignment of other feature of the other sub-team members as the CGAI (The Cross-subgroup Alignment Index) [13]. The IA and CGAI indices range from 0 to 1 .

$$
\mathrm{FLS}=\mathrm{IA} \times(1-\mathrm{CGAI})
$$

The method uses classification data for calculation, so it is necessary to classify the continuity variables. For all the feature variables involved in the calculation, the FLS method cannot determine the membership of a sub-team.

3) Construct Measurement. At present, quantitative measurement is the most widely used methods, and few scholars have developed constructs questionnaires to measure team faultlines. Jehn and Bezrukova (2010) broke through the traditional quantitative calculation method, instead of the measurement questionnaire under the experimental operation, and measured the single-dimensional team faultlines. In this questionnaire, team faultlines is divided into two types: potential faultlines and activated faultlines, and which found that there is no statistical correlation between the potential faultlines and the activated faultlines [4]. In the empirical study of Rupert \& Jehn (2012) [14] and Sun (2015) [15], the questionnaire developed by Jehn and Bezrukova (2010) was also used to measure the perceived team faultlines.

\section{The Effect Mechanism of Team Faultlines}

As mentioned above, there are many differences in the current research conclusions on the effect mechanism of team faultlines. This inconsistency is not only related to the effectiveness, but also the direction of action. This paper reviews from the aspects of outcome variables, mediator and moderator mechanism. 


\subsection{The Impact of Team Faultlines on Team Outcomes}

\subsubsection{Team/Organizational Performance}

Lau and Murnighan (1998) argued that team faultlines can exacerbate conflicts between sub-teams and have negative effect on communication between team members and overall function of organization [1]. In the empirical study of Bezrukova et al. (2009), which pointed out that team faultlines would cause stereotypes and prejudice within the team. Therefore, they thought that the social categorization faultlines and the relationship feature faultlines are negatively correlated with organizational performance [2]. Some studies indicated that excessive faultlines has a negative impact on overall team operations, such as weakening team operations, reducing team performance and satisfaction, and adversely affecting on team learning, information dissemination, and decision making. Therefore, the strength of team faultlines is inversely related to team performance [4] [7] [16]. Earley and Mosakowski (2000) [3]; Li and Hambrick (2005) [5]; Homan et al. (2008) [6]; Thatcher et al. (2003) [8]; Dyck and Starke (1999) [17]; Lau and Murnighan (2005) [9] also had a similar conclusions. The above research is mainly based on the perspective of social categorization. It is considered that individuals use homogeneity and heterogeneity as the categorization criteria for themselves and other members, and then divide the "insiders" and "outsiders" [16], this perspective think that team faultines can exacerbate conflicts between sub-teams, weaken team communication and collaboration, and thus has a negative impact on team/organizational performance.

Contrary to the above studies, some scholars have reached the opposite conclusion. Further research by Lau and Murnighan (2005) pointed out that weak-strength faultlines have a positive effect on communication between sub-teams [9]. Homan's (2007) also pointed out that if team members could understand the value of team diversity, the strength of faultlines has a positive impact on organizational performance [18]. Gibson and Vermeulen (2003), based on an in-depth study of 156 teams, pointed out that moderate-strength team faultlines could promote team learning [7] and improve team effectiveness. Bezrukova et al. (2009) [2]; Thatcher et al. (2003) [8] also drew similar conclusions. The above research is mainly based on the perspective of information processing, which believes that team faultlines can provide diversified knowledge and skills, promote the integration of different information and viewpoints, increase the learning behavior within the team, and improve the satisfaction and the flexibility of thinking of team members, avoid the influence of group thinking, thus improve the effectiveness of decision-making and team performance.

Different from the above, some studies have found that the impact of team faultlines on organizational performance is insignificant. Zhou and Li (2012) found that the correlation between the strength of the faultlines of the board of directors and the innovation strategy of enterprises is insignificant in the high-tech industry [19]; Wang and Xue (2009) believed that team fault-lines is a 
double-edged sword, and play a moderating role in cooperation, team communication, organizational conflicts, and team performance, and the moderating effect is influenced by situational factors such as team tasks, knowledge management, and team leader [20].

\subsubsection{Team Creativity}

As we all know, cognitive diversity is inseparable from team creativity, and the knowledge acquisition and sharing among different sub-teams members will promote the integration of cognitive and stimulate the team creativity [21] [22]. When there are two or more knowledge sub-teams in a team, increasing the balance of the sub-teams or increasing the number of sub-teams can increase the members' consideration of the alternative knowledge, and the sub-team members can have more knowledge to learn and choose, thus, enriching their knowledge reserves constantly through learning of each other, inspiring the creative inspiration, and providing support for improving team creativity [10].

\subsubsection{Team Cohesiveness}

Team cohesiveness is related to the similarity of members in demographic characteristics, abilities and attitudes [17]. When team members differ in certain characteristics, they classify themselves as a sub-team with similar characteristics, and the communication and interaction with outside sub-team members is relatively reduced. Molleman's (2005) study shows that team faultines reduced the attractiveness among sub-teams and damaged the team cohesiveness. The stronger the team faultlines is, the stronger the cohesiveness within the sub-team is, and the greater the negative effect on team operations [23]. Hornsey and Hogg (2000) argued that team cohesiveness is strong when the identities of team members tend to be consistent [24]. When team members feel that their sub-teams are threatened, they don't realize the loyalty to the team, but they put more effort into the sub-team, and the team cohesiveness will be affected. Yoon et al. (1994) argued that when members feel the separation of team identity, it is difficult for them to think that other sub-teams members belong to a whole like themselves, and the team cohesiveness will also be affected [25]. Therefore, in a team with two or more identification-based sub-teams, increasing the number of sub-teams may reduce the identity threat and increase the team identity split. When there are two or more identification-based sub-teams in a team, the number of sub-teams and the team cohesiveness show an "inverted U-shaped" relationship, that is, the appropriate number of sub-teams is good for the team to improve cohesiveness.

\subsubsection{Team Satisfaction}

Team satisfaction is closely related to the emotional integration of team members. For example, Cronin et al. (2011) believed that the emotional integration of team members moderates the impact of sub-team formation on team satisfaction. With the sub-team formation increasing, the emotional integration will weaken, which reduces the team satisfaction [26]. Moreover, studies have shown 
that member's identities and feelings of sub-teams are different, which influences the relationship between the members. Such as, the relationship between the sub-teams is usually tense due to the difference in identity, which is the easiest to create a competitive and antagonistic situation, resulting in conflicts and threats of identity between sub-teams, and reducing the overall team satisfaction [24] Especially in the resource-based sub-teams, the conflict and unfairness will get stronger, due to the irrationality of resource and power allocation, which worsens the relationship between different sub-teams, destroys the atmosphere of cooperation and reduces the satisfaction of the entire team [10].

\subsection{Mediating Mechanism between Team Faultlines and Performance}

\subsubsection{Identity Threat}

Identity threat is a fierce threat atmosphere triggered by the differences and competition between different sub-teams. Due to the difference of identity between different sub-teams, sub-teams members may encounter identification threats from other sub-team members. Especially when there are two opposing identification-based sub-teams, the atmosphere of identity threat is the strongest. However, when three or more such sub-teams exist, the extreme confrontation is broken, and the identity threat tends to dispersion, which greatly reduces the atmosphere of threats and competition [27]. Therefore, increasing the number of sub-teams can reduce the identity threat each other.

\subsubsection{The Convergence of Mental Models}

The convergence of mental models is the fusion in cognitive structures, knowledge structures, or knowledge bases of team members. Cannon-Bowers et al. (1990) argued that when there are multiple knowledge sub-teams in a team, the cognitive and knowledge structure of each sub-teams are different. When different knowledge sub-teams interact, in order to gain more knowledge and information to solve the unsolved problems, team members can benefit from building a common platform to learn knowledge [28]. In fact, this platform is the fusion of the convergence of mental models of different sub-teams. When there are two or more knowledge sub-teams in a team, increasing the balance of the sub-team will reduce the fusion of the convergence of mental models, while increasing the unbalance will increase the convergence of mental models [29].

\subsubsection{Sub-Team Conflicts}

Polzer et al. (2006) found that team faultlines exacerbates resource competition among sub-teams and strengthens team conflicts. When conflict occurs and harms the benefit of some people, they will seek help from the sub-teams they belong to, which will exacerbate the differentiation of benefit among members and increase the negative impact on the team [27]. In addition, the relationship between the faultlines and the team conflict is affected by the relative size of the sub-team [8]. If the scale of the sub-teams is disparity, the large-scale sub-teams will receive more insider support and have more right in decision-making. 
Usually, they will not regard the less sub-team as the forces of threat; the little sub-team may hide their own opinions to obey the public opinion considering social acceptance. If the size gap is small, the sub-teams are easy to tit-for-tat, and intensify conflicts and go to extremes [27]. As a result, sub-teams of varying sizes have fewer conflicts and higher performance than sub-teams of comparable size [11].

\subsubsection{Centralization of Authority}

Centralization of authority is that the resources and authority within a team are gradually concentrated to individual sub-teams. Bunderson and Boumgarden (2010) argued that when multiple resource-based sub-teams exist in a team with uneven distribution of resources and authority, individual sub-teams have a large amount of resources and absolute dominance, so that the team operation tends to follow their pace general, which directly leads to the strengthening of centralization of authority [30]. Increasing the distribution uniformity of authority and resource will greatly relieve the situation of centralization of authority.

\subsubsection{Cross-Team Learning}

Gibson and Vermeulen (2003) believed that every sub-team member has to face problem of team learning. In order to learn how to solve certain problems, sub-team members have to actively interact with other sub-teams, during which learning, sharing and integrating each other's opinions, or reaching an agreement on the implementation of a specific solution [7]. Therefore, during the operation of the team, different types of sub-teams tend to cross the team and learn from other sub-teams to make up for their knowledge gap. For knowledge-based sub-teams, Wilson et al. (2007) argued that increasing alternative sources of knowledge facilitates cross-team learning because it provides ideas to solve the team tasks [31]. However, the increasing of sub-teams number will lead to increase alternative sources of knowledge and reduce the convergence of mental models. If we want both processes to have the greatest spillover for team learning, the number of knowledge-based sub-teams must be con-trolled to a reasonable scope. Therefore, the number of knowledge-based sub-teams and team learning are "inverted U-shaped" relationship.

\subsubsection{Team Communication}

Team communication is an important channel for absorbing the rich information, however, the stronger the faultlines it is, the less communication between the sub-teams becomes, because the cognitive biases on different sub-team members is not good for internal communication within the team. When there is a weak faultlines, if members perceive different views, they will be worried that they may not be supported by others, thus, they will not share diversified information. In contrast, in a moderately faultlines team, the communication between members helps break the boundaries between sub-teams and improves team performance [7]. In this type of team, the members in different sub-teams are similar in some characteristics, which can reduce communication barriers 
caused by clear boundaries, promote communication between sub-teams, and easily obtain support of sub-teams members, enhance the motivation for information sharing.

\subsection{Situational Factors of Team Faultlines on Performance}

\subsubsection{Task Interdependence}

Task interdependence affects the integration of diverse knowledge and experience among team members. High task interdependence can overcome the communication problems between the sub-teams under the strong faultlines, and bring more assistance and information sharing behavior. For teams with medium strength faultlines, the impact of task interdependence on the team (compared to the strong faultlines) is relatively lesser, because in which even if the task interdependence is not strong, sub-team members also can increase the communication and strengthen the information exchange between members [32].

\subsubsection{Team Knowledge Management System}

Studies have shown that too strong or too weak faultlines is not good for team learning and innovation. Strong faultlines results in lacking trust, sharing willingness and cohesiveness among the sub-teams; while the members under weak faultlines have insufficient similarity and poor mutual understanding ability, which is difficult to identify and absorb the valuable information of other sub-teams. The knowledge management system moderates the affection of faultlines on team learning. If the strength of team faultlines is suitable, minor differences make it is possible for members in sub-teams to share and absorb knowledge among sub-teams. Therefore, through the knowledge management system, it is beneficial to learn from each other and improve team performance [33].

\subsubsection{Management of External Leaders}

The involvement of external leaders can weaken the influence of faultlines on the team [27]. External leader is the leader that the team needs to report, although he/she does not directly participate in the team management, but he/she can promote the self-monitoring and self-assessment of the team, and create a good atmosphere for team development. As mentioned earlier, compared with the medium-strength faultlines, the motivation of the team members to learn from each other is insufficient in the strong or weak faultlines. At this time, if there is external leader to motivate and guide the team learning behavior, the effect of mutual learning among different sub-teams members will be greatly improved, and the positive impact on team performance will be greater. In contrast, internal leaders are within the team, whose management measures are likely to cause conflicts between team members, and the moderating effect on the faultlines is relatively poor.

\subsubsection{Properties of Sub-Team Structure}

Differences in the strength and distance of team faultlines lead to differences structural properties of the sub-teams on quantity, balance, and uniformity. 
1) Quantity. Some scholars believe that when there are two sub-teams in a team, it is the most harmful, because there will be a fierce competition situation, that is us vs. them [27]. Relative to multiple sub-teams, there will be a strong conflict process be-tween the two sub-teams, which is not good for teamwork. But this view is inconsistent with another view that "the situation is the worst when there are no sub-teams in a team" [21]. With the development of research, Carton and Cummings (2012) found that the impact of sub-teams' number should also be based on the sub-teams' type, different types of sub-teams will have a unique impact on their own team process [10].

2) Balance. Different scholars hold different views on the impact of sub-team balance on the team process and outcomes. Some scholars believe that the balance of sub-teams is more beneficial to the interaction between sub-teams, which makes the team operation more effective and improves the possibility of achieving effective results, because the unique views and ideas of different sub-teams will be considered accordingly [10]. The other scholars' opinions are just the opposite, they think that the sub-team's imbalance is more effective for the team process and results, because the sub-teams with the imbalanced size will reach a tacit agreement that the weak sub-team often chooses to "follow" and "submissive" strong sub-teams, thus reducing unnecessary conflicts and competition among sub-teams, even promoting good team operations [4].

3) Uniformity. With regard to the moderating effect of sub-team uniformity on the sub-team process, the scholars mainly investigate the influence of the distribution about knowledge resources, communication and other behaviors of the team members in uniformity and non- uniformity conditions. First of all, when the resources are unevenly distributed within the team and the sub-teams are under non- uniformity states, sub-teams due to knowledge and resource faultlines is easier to form. These sub-teams will have some negative effects on team learning and collective cognition [5] [6] [9], which will further weaken team effectiveness. When the uniformity is high, the probability of forming a sub-team with clear boundaries is greatly reduced, which is easier for the team to form a sense of equality, under which team members are more willing to learn from other sub-teams and reduce the uncooperative behavior. At the same time, Centola and Macy (2007) also believed that smooth team communication can weaken members' perception of competition, increase the willingness to share knowledge among different sub-teams, and help to form a shared mental model, and help members to learn the tacit knowledge [34].

\subsubsection{Individual Attributes of Members}

1) The status of team member. Lau and Murnighan (1998) believed that when different sub-teams are divided according to the power, conflicts and tensions will be increased during the growth of the sub-teams, resulting in sub-teams are not willing to learn across sub-teams, ethnocentrism and departmentalism prevailed, which is not benefit to the cohesion and learning of the entire team [1]. Ely and Thomas (2001) believed that equal status is the guarantee for communi- 
cation and learning between different sub-teams. Team members will better understand each other's tasks and differences in an equal atmosphere and improve the initiative of learning each other [35].

2) Diversity beliefs are the evaluation of diversified values. Homan et al. (2007) argued that the degree of preference and sup-port for diverse teams (sub-teams) is different due to the different ideas on diversity beliefs, which affects the relationship be-tween team diversity and team performance [18]. At the same time, Meyer and Schermuly (2012) found that the team can overcome the negative impact of team faultlines on team performance only if the team members are highly task motivation and they are positive about the value of the diversification [36]. Therefore, the diversity beliefs affect the attitude of team members to the sub-teams, which will have a certain impact on the team operation.

\subsubsection{Team Innovation Atmosphere}

Team innovation atmosphere is the working environment and atmosphere that exists within the team and can be perceived by the team members. It can promote the innovation ability and maintain the persistence of innovative behavior [37]. This kind of atmosphere is mainly formed by in-depth interaction in order to achieve common goals which can not only effectively predict employee job satisfaction, turnover rate, etc., but also motivate enthusiasm to create and improve the creativity of the entire team. Gilson and Shalley (2004) believed that the team innovation atmosphere can adjust the interaction between different sub-teams to a certain extent, guide them to develop toward common goals, increase mutual trust and satisfaction through communication and learning, and create an atmosphere of team innovation to motivate members to innovate constantly [22]. Therefore, the team innovation atmosphere as a situation factor can improve the interaction between different sub-teams, team creativity and cohesiveness.

\subsubsection{The type of Sub-Team}

Carton and Cummings (2012) argued that different types of sub-teams have different effects on sub-team processes due to their unique attributes [10] [38]. For teams with two or more identification-based sub-teams, team performance declines as the balance of the identification-based sub-team increases [27] [39], however the knowledge sub-team is the opposite [38]. The structural attributes of the sub-team also indirectly affect the team processes and outcomes by moderating the type of sub-teams [7] [21]. Therefore, the impact of the faultlines on team performance is determined by the type and structural attributes of sub-teams.

\section{Research Prospect}

\subsection{Improving the Measuring Method of Team Faultlines}

As has been noted, the measurement of team faultlines is still an unsolved prob- 
lem in academia. Qualitative measurement lacks a quantifiable method, the calculation of quantitative measurement is extremely cumbersome, and it cannot solve the conditions that contain more features and more people, whose availability is limited. Both qualitative and quantitative measurements are not able to solve the measurement problem of the team faultlines. Therefore, developing a scientific, practicable and simple measuring method is still a key technical problem in this field. Therefore, we believe that we should advocate from the mathematical measurement of the potential faultlines to the constructs measurement of the activated faultlines, and cross-validate the existing measurement methods in order to develop a more scientific and effective measurement tool. This paper suggests as follow:

1) Reduce the influence of the correlation of characteristic variables on the faultlines. The characteristic variables used to calculate the strength of the faultlines may have a certain correlation. If it is not considered, the faultlines inside the team will be excessively enlarged or ignored.

2) Consider the dynamic changes of the faultlines. Due to the influence of emotional factors on their sense of belonging, the faultlines within the team is also constantly changing. Therefore, the calculation method based on the fixed demographic characteristics of team members has certain limitations. Even if the emotional factors are considered in the process of calculating the faultines, the faultlines is only at a certain time, which is difficult to reflect the changes of the members between the sub-groups.

3) Introduce the activator of faultlines. The same faultines has different effects on team performance under activation and dormancy, so the strength of the faultlines in different states should also be different. Introducing the activation factor of faultlines can make the calculated strength more accuracy, but how to determine the effective activation factors remains to be further explored.

\subsection{Further Study the Mechanism of Team Faultlines}

As can be seen from the previous literature review, the findings about the influence of team faultlines on team performance are inconsistent. There are possible reasons: First, feature selection of the team's faultines is not consistent. Different researchers have examined different types of team faultlines, some examine the surface features, and some examine the deep features, which led to inconsistent conclusions. Second, the researchers did not distinguish between potential faultlines and activated faultlines, while Jehn and Bezrukova (2010) pointed out that the correlation between potential and activation faultlines is not statistically significant [4], which raised questions about the previous conclusions that did not distinguish between potential and activated faultlines. Finally, there is no distinction between the strength of team faultlines, which have different effects on the team process [7], so the conclusions are inconsistent. The future research about the mechanism of faultlines can be carried out in the following aspects:

1) A combination of different research perspective. From the existing research 
on how team faultlines affect team effectiveness is obviously insufficient. Most of which is still at the level of exploring whether the faultlines promotes or hinders the team efficiency. Only a few studies focus on process or mechanism that how team faultlines affects team effectiveness based on social categorization perspective, there are only a handful of empirical studies based on information processing perspectives, and whose conclusions need to be supported by more robust empirical data. Therefore, we can start from the social categorization and information processing theory, carry out the competitive hypothesis test on the mediating mechanism of team faultlines in the same empirical research, and analyze how team faultlines affect team output to reverse the inconsistency of research conclusions.

2) Investigate the mediating and moderating mechanism between team faultlines and team performance. Most of the existing researches on team faultines focus on the main effect of team faultlines e on team performance, and there are few studies to investigate the mediating and moderating mechanism between them, which makes the causal relationship incomplete and ambiguous. Therefore, it is necessary for future research to combine a large number of mediator and moderator variables to examine the relationship between team faultlines and team performance. In particular, the research on the mediating mechanism between team faultlines and the team effectiveness based on the information processing perspective is almost blank, which leaves a lot of room for future research.

3) Improve the current research paradigm about the mechanism of team faultlines. The traditional input-process-output paradigm ignores the positive feedback effect of teamwork effectiveness (such as the impact of the previous performance on the evolution of the later faultlines), so it is necessary to improve this paradigm in future studies. The input- mediating variable -output-input paradigm is used to explore how the previous teamwork output affects the dynamic evolution in next stage, thus more comprehensively examining the mechanism of team faultlines.

4) Conduct a cross-level study of team faultlines. At present, the relevant research on team faultlines, whose result variables are mostly team level variables such as team performance, creativity, and cohesiveness, which rarely involve research outside the team. In fact, the factors of team level as the situational factors embedded in individual members also play an important role in individual output. Therefore, it is necessary for future to research on the relationship between team faultlines and individual characteristics of team members, such as individual creativity and performance. At the same time, we should carry out the research on relationship between team faultlines and organizational level variables, such as internal and external environ-mental characteristics of enterprises.

\subsection{Further Study of the Activation Mechanism of Team Faultlines}

Whether the potential faultlines is activated and functioning often depends on 
the task situation of team [1]. For example, Lau and Murnighan (1998) argued that the organizational reform may activate age and old-fashioned factors to form new faultlines. That team pay attention to members' career development may induce faultlines formed by factor of gender [1]. Many follow-up studies have repeatedly emphasized that there are multiple potential faultines in the team, but only the activated faultlines will have an effect on team processes and outcomes [32]. In other words, only in certain situations, a specific type of faultlines will divide the team into multiple sub-teams, which will affect team effectiveness. Unfortunately, so far, almost all scholars are conducting research on potential faultlines in addition to the initial exploration of Jehn and Bezrukova (2010) [4], no other empirical researches on how team faultlines is activated have been found (only sporadic theoretical derivation). Therefore, there are no systematic theoretical explanations for the problems that how and why different types of team faultlines are activated. In addition, Jehn and Bezrukova (2010) also shows that there is no statistical correlation between the potential faultines and the activated faultlines [4], and the potential faultlines does not have a substantial impact on organizational behavior and organizational performance. Therefore, the isolated study potential faultlines has no theoretical value. In other words, if we can answer the question that how different types of team faultlines are activated in different situations, especially to identify potential faultlines that are beneficial or hinder to improve team performance, and find their activation mechanism, which will be a great significance thing for both team theory development and team management practice.

\subsection{Improve Existing Research Methods of Team Faultlines}

1) From cross-sectional research to longitudinal research. As mentioned above, the current research on team faultlines shows the tendency from the surface features to the deep features of the team members, from the social categorization features to the information processing features, from static features to the dynamic features. Gratton et al. (2007) argued that the feature properties of team faultlines change dynamically as the team develops [32]. The present researches mainly pay attention to the surface faultlines based on demographic characteristics, and the research on deep faultlines is insufficient. Therefore, it is necessary to study team faultlines from the original cross-sectional design to the dynamic tracking study. Through the longitudinal tracking and multi-stage repeated measurement for team faultlines as the team evolution to test the dynamic evolution mechanism of team faultlines.

2) Cross-validation through multiple research methods. Experiments have unique advantages in terms of internal validity, but they are usually carried out in an artificial environment with low relevance to reality, and all the participants are temporary teams whose external validity is debatable. The actual relevance of field study is high, but its internal validity is limited due to lack of control. In order to achieve the high quality balance of various validities, the idea of 
cross-validation through multiple methods should be introduced in the research. Most of the existing research about faultlines belongs to the simulation experiment. Although it activated and handled the various team faultlines, whose external validity has been questioned; while the few existing field studies are mostly concerned the unconvincing potential faultlines, but it does not focus on the faultlines that has been activated. Therefore, the existing research is not enough to allow us to reach a solid theoretical consensus, in order to obtain a stable causal relationship conclusion, we should use multiple methods to cross validate in the future.

\subsection{Research on Team Faultlines Based on China Specific Cultural Background}

In China, the phenomenon of "small groups" and "cliques" is very common. People show a high degree of collectivism to "in-sider" and extreme individualism to "outsiders" [39]. Therefore, the research based on Chinese cultural background is likely to draw different conclusions from western studies. Under the Chinese context, the sub-team process is generally more conflict and uncoordinated than the west [39]. For another example, the sub-team composition will change during the process of team evolution. Leaders especially value the loyalty of subordinates in China, which may make it difficult to change the composition of sub-teams within the team once formed [39]. Compared with westerners, Chinese people not only like to divide team boundaries, but also are less willing to cooperate with "outsiders", which may lead to management measures proposed to pro-mote positive sub-team processes and cooperation between sub-teams do not work in China [39]. At present, it's very rare to conduct research on team faultlines in combination with China specific cultural background, which requires scholars to explore in the future.

\section{Conclusions}

As mentioned earlier, team faultlines which has better explanatory ability than team heterogeneity as an important variable in team construction research, has attracted many scholar's' attentions. However, there is no simple and scientific method accepted by scholars. Furthermore, the study of team faultlines has not reached a consensus based on different research perspectives. Therefore, this paper puts forward some suggestions for future research from the aspects of measurement and research method, effect and activation mechanism.

With the development of the team, the features that form team faultines will change, and the utility of deep faultlines may become more and more obvious. The initial faultlines strength, the enrollment of new members and the departure of important members may all affect the evolution and development of the faultlines. Unfortunately, this paper fails to review the evolution rule of team faultlines. Therefore, in addition to the above research prospects, the evolution rule of team faultlines is also the entry point of the author's future research. 


\section{Conflicts of Interest}

The authors declare no conflicts of interest regarding the publication of this paper.

\section{References}

[1] Lau, D.C. and Murnighan, J.K. (1998) Demographic Diversity and Faultlines: The Compositional Dynamics of Organizational Groups. The Academy of Management Review, 23, 325-340. https://doi.org/10.5465/amr.1998.533229

[2] Bezrukova, K., et al. (2009) Do Workgroup Faultlines Help or Hurt? A Moderated Model of Faultlines, Team Identification, and Group Performance. Organization Science, 20, 35-50. https://doi.org/10.1287/orsc.1080.0379

[3] Earley, P.C. and Mosakowski, E. (2000) Creating Hybrid Team Cultures: An Empirical Test of Transnational Team Functioning Creating Hybrid Team Cultures: An Empirical Test of Transnational Team Functioning. The Academy of Management Journal, 43, 26-49.

[4] Jehn, K.A. and Bezrukova, K. (2010) The Faultline Activation Process and the Effects of Activated Faultlines on Coalition Formation, Conflict, and Group Outcomes. Organizational Behavior and Human Decision Processes, 112, 24-42. https://doi.org/10.1016/j.obhdp.2009.11.008

[5] Li, J.T. and Hambrick, D.C. (2005) Factional Groups: A New Vantage on Demographic Faultlines, Conflict, and Disintegration in Work Teams. Academy of Management Journal, 48, 794-813. https://doi.org/10.5465/amj.2005.18803923

[6] Homan, A.C., et al. (2008) Facing Differences with an Open Mind: Openness to Experience, Salience of Intra-Group Differences, and Performance of Diverse Work Groups. Academy of Management Journal, 51, 1204-1222. https://doi.org/10.5465/amj.2008.35732995

[7] Gibson, C. and Vermeulen, F. (2003) A Healthy Divide: Subgroups as a Stimulus for Team Learning Behavior. Administrative Science Quarterly, 48, 202-239. https://doi.org/10.2307/3556657

[8] Thatcher, S., et al. (2003) Cracks in Diversity Research: The Effects of Diversity Faultlines on Conflict and Performance. Group Decision and Negotiation, 12, 217-241. https://doi.org/10.1023/A:1023325406946

[9] Lau, D.C. and Murnighan, J.K. (2005) Interactions within Groups and Subgroups: The Effects of Demographic Faultlines. Academy of Management Journal, 48, 645-659. https://doi.org/10.5465/amj.2005.17843943

[10] Carton, A.M. and Cummings, J.N. (2012) A Theory of Subgroups in Work Teams. Academy of Management Review, 37, 441-470. https://doi.org/10.5465/amr.2009.0322

[11] Cramton, C.D. and Hinds, P.J. (2004) Subgroup Dynamics in Internationally Distributed Teams: Ethnocentrism or Cross-National Learning? Research in Organizational Behavior, 26, 231-263. https://doi.org/10.1016/S0191-3085(04)26006-3

[12] Barkema, H.G. and Shvyrkov, O. (2007) Does Top Management Team Diversity Promote or Hamper Foreign Expansion? Strategic Management Journal, 28, 663-680. https://doi.org/10.1002/smj.604

[13] Shaw, J.B. (2004) The Development and Analysis of A Measure of Group Faultlines. Organizational Research Methods, 7, 66-100. https://doi.org/10.1177/1094428103259562 
[14] Rupert, J. and Jehn, K.A. (2012) When Subgroups Fuse and Divide: Effects of Faultlines on Team Learning and Customer Satisfaction. [Working Paper] https://works.bepress.com/etty_jehn/22/

[15] Sun, H.L. (2015) Research on Team Faultlines and Innovation Performance of New Product Development Teams: The Moderating Roles of Swift Trust and Knowledge Transfer Channel. The Theory and Practice of Finance and Economics, 36, 126-132.

[16] Rico, R., et al. (2007) The Effects of Diversity Faultlines and Team Task Autonomy on Decision Quality and Social Integration. Journal of Management, 33, 111-132. https://doi.org/10.1177/0149206306295307

[17] Dyck, B. and Starke, F.A. (1999) The Formation of Breakaway Organizations: Observations and a Process Model. Administrative Science Quarterly, 48, 792-822. https://doi.org/10.2307/2667056

[18] Homan, A.C., et al. (2007) Bridging Faultlines by Valuing Diversity: Diversity Beliefs, Information Elaboration, and Performance in Diverse Work Groups. Journal of Applied Psychology, 92, 1189-1199. https://doi.org/10.1037/0021-9010.92.5.1189

[19] Zhou, J. and Li, X.Q. (2012) Empirical Study on the Effect of Cognitive Heterogeneity of Board on Firm Innovation Strategy. Journal of Management Science, 25, 1-12.

[20] Wang, D.X. and Xue, H.J. (2009) Group Faultlines in Diverse Teams: A Study of Its Emergence, Development and Effect. Journal of Zhejiang University (Humanities and Social Sciences), 39, 122-128.

[21] Polzer, J.T., et al. (2002) Capitalizing on Diversity: Interpersonal Congruence in Small Work Groups. Administrative Science Quarterly, 47, 296-324.

https://doi.org/10.2307/3094807

[22] Gilson, L.L. and Shalley, C.E. (2004) A Little Creativity Goes a Long Way: An Examination of Teams' Engagement in Creative Processes. Journal of Management, 30, 453-470. https://doi.org/10.1016/j.jm.2003.07.001

[23] Molleman, E. (2005) Diversity in Demographic Characteristics, Abilities and Personality Traits: Do Faultlines Affect Team Functioning? Group Decision and Negotiation, 14, 173-193. https://doi.org/10.1007/s10726-005-6490-7

[24] Hornsey, M.J. and Hogg, M.A. (2000) Assimilation and Diversity: An Integrative Model of Subgroup Relations. Personality and Social Psychology Review, 4, 143-156. https://doi.org/10.1207/S15327957PSPR0402_03

[25] Yoon, J., et al. (1994) Interpersonal Attachment and Organizational Commitment: Subgroup Hypothesis Revisited. Human Relations, 47, 329-351. https://doi.org/10.1177/001872679404700305

[26] Cronin, M.A., et al. (2011) Subgroups within a Team: The Role of Cognitive and Affective Integration. Journal of Organizational Behavior, 32, 831-849. https://doi.org/10.1002/job.707

[27] Polzer, J.T., et al. (2006) Extending the Faultline Model to Geographically Dispersed Teams: How Colocated Subgroups Can Impair Group Functioning. Academy of Management Journal, 49, 679-692. https://doi.org/10.5465/amj.2006.22083024

[28] Cannon-Bowers, J.A., et al. (1990) Cognitive Psychology and Team Training: Training Shared Mental Models and Complex Systems. Human Factors Society Bulletin, 33, 1-4.

[29] Okhuysen, G.A. and Bechky, B.A. (2009) 10 Coordination in Organizations: An Integrative Perspective. The Academy of Management Annals, 3, 463-502. https://doi.org/10.5465/19416520903047533

[30] Bunderson, J.S. and Boumgarden, P. (2010) Structure and Learning in Self-Managed 
Teams: Why "Bureaucratic" Teams Can Be Better Learners. Organization Science, 21, 609-624. https://doi.org/10.1287/orsc.1090.0483

[31] Wilson, J.M., et al. (2007) Group Learning. Academy of Management Review, 32, 1041-1059. https://doi.org/10.5465/amr.2007.26585724

[32] Gratton, L. and Voigt, A. (2007) Erickson T. Bridging Faultlines in Diverse Teams. Sloan Management Review, 48, 22-29.

[33] De Dreu, C.K.W. and West, M.A. (2001) Minority Dissent and Team Innovation: The Importance of Participation in Decision Making. Journal of Applied Psychology, 86, 1191-1201. https://doi.org/10.1037/0021-9010.86.6.1191

[34] Centola, D. and Macy, M. (2007) Complex Contagions and the Weakness of Long Ties. The American Journal of Sociology, 113, 702-734. https://doi.org/10.1086/521848

[35] Ely, R.J. and Thomas, D.A. (2001) Cultural Diversity at Work: The Effects of Diversity Perspectives on Work Group Processes and Outcomes. Administrative Science Quarterly, 46, 229-273. https://doi.org/10.2307/2667087

[36] Meyer, B. and Schermuly, C.C. (2012) When Beliefs Are Not Enough: Examining the Interaction of Diversity Faultlines, Task Motivation, and Diversity Beliefs on Team Performance. European Journal of Work and Organizational Psychology, 21, 456-487. https://doi.org/10.1080/1359432X.2011.560383

[37] Fang, L.T., et al. (2012) Review on Team Innovation Climate. Science Research Management, 33, 146-153.

[38] Carton, A.M. and Cummings, J.N. (2013) The Impact of Subgroup Type and Subgroup Configurational Properties on Work Team Performance. Journal of Applied Psychology, 98, 732-758. https://doi.org/10.1037/a0033593

[39] Xie, X.Y., et al. (2012) The Research Progress of Subgroup Relationship under the Background of Team. Foreign Economics \& Management, 34, 22-29. 